\title{
Generation of functional CD8+ T Cells by human dendritic cells expressing glypican-3 epitopes
}

\author{
James O'Beirne 1,3, Farzin Farzaneh² and Phillip M Harrison*1
}

\begin{abstract}
Background: Glypican 3 (GPC-3) is an oncofoetal protein that is expressed in most hepatocellular carcinomas (HCC). Since it is a potential target for T cell immunotherapy, we investigated the generation of functional, GPC-3 specific T cells from peripheral blood mononuclear cells (PBMC).

Methods: Dendritic cells (DC) were derived from adherent PBMC cultured at $37^{\circ} \mathrm{C}$ for 7 days in X-Vivo, $1 \%$ autologous plasma, and $800 \mathrm{u} / \mathrm{ml}$ GM-CSF plus $500 \mathrm{u} / \mathrm{ml} \mathrm{IL-4.} \mathrm{Immature} \mathrm{DC} \mathrm{were} \mathrm{transfected} \mathrm{with} 20 \mathrm{\mu g}$ of in vitro synthesised GPC3 mRNA by electroporation using the Easy-ject plus system (Equibio, UK) (300 V, $150 \mu \mathrm{F}$ and $4 \mathrm{~ms}$ pulse time), or pulsed with peptide, and subsequently matured with lipopolysaccharide (LPS). Six predicted GPC-3 peptide epitopes were synthesized using standard f-moc technology and tested for their binding affinity to HLA-A2.1 molecules using the cell line $\mathrm{T} 2$.

Results: DC transfected with GPC-3 mRNA but not control DC demonstrated strong intracellular staining for GPC-3 and in vitro generated interferon-gamma expressing T cells from autologous PBMC harvested from normal subjects. One peptide, GPC-3 ${ }_{522-530}$ FLAELAYDL, fulfilled our criteria as a naturally processed, HLA-A2-restricted cytotoxic T lymphocyte (CTL) epitope: i) it showed high affinity binding to HLA-A2, in T2 cell binding assay; ii) it was generated by the MHC class I processing pathway in DC transfected with GPC-3 mRNA, and iii) HLA-A2 positive DC loaded with the peptide stimulated proliferation in autologous T cells and generated CTL that lysed HLA-A2 and GPC-3 positive target cells.

Conclusions: These findings demonstrate that electroporation of GPC-3 mRNA is an efficient method to load human monocyte-derived DC with antigen because in vitro they generated GPC-3-reactive T cells that were functional, as shown by interferon-gamma production. Furthermore, this study identified a novel naturally processed, HLA-A2restricted CTL epitope, GPC-3 $522-530$ FLAELAYDL, which can be used to monitor HLA-A2-restricted CTL responses in patients with HCC. Further studies are required to investigate whether anti-GPC-3 immunotherapy has a role in the treatment of GPC-3 dependent tumours, such as HCC.
\end{abstract}

\section{Background}

Increasing evidence suggests that immune responses play an important role in the control of cancer and manipulation of the immune system to recognize and attack cancer cells may be a valuable form of therapy [1]. Hepatocellular carcinoma (HCC), which is the third most common cause of cancer death world-wide [2], is a potential target for immunotherapy [3] because there are numerous documented cases of spontaneous regression [4] and the

\footnotetext{
* Correspondence: phillip.harrison@kcl.ac.uk

1 Department of Liver Studies \& Transplantation, Kings College London, Denmark Hill Campus, Bessemer Road, London, SE5 9RS, UK Full list of author information is available at the end of the article
}

presence of cytotoxic tumour infiltrating lymphocytes (TIL) at histological examination is associated with a better prognosis after liver resection or transplantation [5]. Infusion of $\mathrm{T}$ lymphocytes, activated with anti CD3 and interleukin 2 (IL2), improved disease-free survival after $\mathrm{HCC}$ resection, suggesting a role for $\mathrm{T}$ cell immunotherapy in this setting [6]. However, current methods of isolation and in vitro expansion of $\mathrm{T}$ lymphocytes are cumbersome and expensive, and the durability of any anti-tumour immune response induced by administration of non-antigen specific, in vitro expanded $\mathrm{T}$ cells is unknown [7]. 
Many tumours, including HCC, express tumour-associated antigens (TAA) that might serve as potential targets for antigen-specific $\mathrm{T}$ cell immunotherapy. Glypican 3 (GPC-3), a 580 amino acid glycosylphosphatidylinositollinked heparan sulphate proteoglycan, is expressed in foetal liver and plays an important role in foetal development because it facilitates the interaction of growth factors with their cognizant receptors [8]. It is rarely detected in adult liver but is reactivated in $72 \%$ of HCC [9], where its expression is correlated with a poor prognosis [10]. Intradermal vaccination of BALB/c mice with a GPC-3 peptide (EYILSLEEL), restricted to the murine MHC-I molecule $\mathrm{H}-2 \mathrm{~K}^{\mathrm{d}}$, mixed with incomplete Freund's adjuvant induced epitope specific, cytotoxic T lymphocytes (CTL) [11] and immunization using dendritic cells (DC) pulsed with this peptide prevented the growth of GPC-3 positive tumours [12]. Mice vaccinated with DC expressing GPC-3 as a transgene were also found to have protective immunity against subsequent challenge with GPC-3 positive melanoma cells [13]. In a study of 20 HCC patients treated with locoregional therapy, 16 (80\%) were found to have TAA-specific CD8+ T cells, including $\mathrm{T}$ cells directed against GPC-3 [14]. Furthermore, the magnitude of the TAA-specific CD8+ T-cell response was a significant independent prognostic factor for tumour-free survival. These data suggest that GPC-3 is a novel $\mathrm{HCC}$-associated antigen but further studies are required to investigate the immunogenicity of human GPC-3 and to establish any therapeutic potential.

In this study, we demonstrate that human monocytederived DC expressing GPC-3 antigen are able to induce, in vitro, GPC-3-reactive $\mathrm{T}$ cells that are functional, as shown interferon-gamma production. We also describe a novel naturally processed, immunogenic epitope, GPC$3_{522-530}$ FLAELAYDL, which is restricted to HLA-A2, a common class 1 allele in various ethnic groups, including Asians and Caucasians.

\section{Methods}

\section{Cell lines}

T2 cells $(H L A-A * 0201)$ and the human hepatocellular carcinoma cell line HepG2 (HLA-A*0201 and GPC-3 positive) were obtained from ATCC and expression of HLAA2 and GPC-3 confirmed in the latter using flow cytometry, after staining with monoclonal antibodies against HLA-A2.1 (BB7.2, Dako, UK), and GPC-3 (Biomosaics Inc, Burlington, USA), respectively (data not shown). The cell lines were cultured in RPMI (Gibco, UK) or DMEM (Cambrex, UK), respectively, supplemented with $10 \%$ foetal calf serum (FCS) (Cambrex, UK) and antibiotics (penicillin G $100 \mathrm{IU} / \mathrm{ml}$ and Streptomycin $50 \mu \mathrm{g} / \mathrm{ml}$ ).

\section{T2 binding assays}

The prediction tools SYFPEITHI [15] and HLAmotif [16] were used to reveal GPC-3 peptide epitopes with predicted strong binding to HLA-A2. The top 30 peptides were reassessed using RankPep [17], which also predicts epitopes generated by the proteasome, and 6 peptide epitopes were selected (Table 1). These peptides were synthesized using standard f-moc technology (>95\% purity, as determined by reverse phase HPLC; Sigma, UK), along with an AFP-derived, HLA-A2-binding peptide (GVALQTMKQ) [18], and a random, non-HLA-A2 binding, control peptide (RGYVYQGL). The AFP peptide has only one anchor but is an "immunodominant" epitope [19] and its use was convenient because $\mathrm{T}$ cells reactive to this epitope have been shown to lyse HepG2 cells. Due to the hydrophobicity of peptides binding to HLA-A2, the lyophilized peptides were resuspended in DMSO at 10 $\mathrm{mM}$.

The selected epitopes were tested for their binding affinity to HLA-A2.1 molecules using the cell line T2, which is deficient in TAP1 and TAP 2 (transporters associated with antigen processing 1 and 2) [20]. Although T2 cells express very low levels of HLA-A2.1 molecules under normal culture conditions, cell surface expression

Table 1: GPC-3 peptides predicted to bind to HLA-A2 and be processed by the proteasome, and control peptides used in the study

\begin{tabular}{llll}
\hline & GPC-3 peptide & Position & Sequence \\
\hline 1 & $229-237$ & FLQALNLGI \\
& 2 & $522-530$ & FLAELAYDL \\
& 3 & $299-307$ & YILSLEELV \\
& 4 & $186-194$ & GLPSALDI \\
& 5 & $222-230$ & SLQVTRIFL \\
AFP peptide & 6 & $169-177$ & ELFDSLFPV \\
Control peptide & & & GVALQTMKQ \\
\hline
\end{tabular}


is upregulated when appropriate peptides bind and stabilize the HLA-A2.1 molecule. Thus, up-regulation of HLA-A2.1 expression in T2 cells by a peptide is regarded as an indication of it being an HLA-A2.1-restricted epitope [19]. HLA-A2.1 expression on the T2 cell surface was quantified by staining the cells with HLA-A2-specific antibody $(1 \mu \mathrm{g} / \mathrm{ml})$, as described [21]. To assess the stability of the HLA-A2-peptide complex, $1 \times 10^{5} \mathrm{~T} 2$ cells were incubated for 3 hours at $37^{\circ} \mathrm{C}$ with various concentrations of peptide, $5 \mathrm{nM} \beta_{2}$ microglobulin and $5 \mu \mathrm{g} / \mathrm{ml}$ Brefeldin A, which inhibits the transportation of protein through the Golgi and hence blocks delivery of new MHC class I molecules to the cell surface. Cells were washed at the end of each time point and stained for cell surface HLAA2 expression and then analyzed by flow cytometry.

\section{Construction of RNA expression vector and in vitro transcription of mRNA}

An RNA expression vector was constructed on the backbone of the PGEM 5Z(+) vector (Promega, Southampton, UK). A 76 nucleotide poly-A sequence was cloned into the vector between the Sph1 and Apal sites and a sequence containing a new multiple cloning cassette and the 3' untranslated region of the human $\alpha$-globin gene, to increase the intracellular stability of mRNA transcripts [22], was inserted between the Sac1 and Sph1 sites. Subsequently, the cDNA sequences encoding the open reading frames of either GPC-3 or enhanced green fluorescent protein (eGFP) were inserted between Nhe1 and Age1 sites in the new cloning cassette, downstream of the SP6 promoter site of PGEM5Z and upstream of the mRNA stabilizing sequences (Figure 1a). The $1.74 \mathrm{~kb}$ GPC-3 open reading frame sequence was generated by PCR from reverse transcribed RNA extracted from HepG2 cells using primers 5'-CGAGCTAGCATGGGCCGGGACCGTG and 5'-AGGACCGGTGTGCACCAGGAAGAAGAAGC, which incorporated restriction sites for Nhe1 and Age1, respectively. The vector was sequenced to confirm authenticity.

The vector was linearized using a SnaB1 restriction site, which is immediately downstream of the poly A sequence, and the resulting linear DNA was isolated by gel extraction. Following the manufacturers instructions, the linear DNA $(1 \mu \mathrm{g})$ served as template in an SP6 mMessage Machine reaction (Ambion, Huntingdon, UK). After 3 hours at $37^{\circ} \mathrm{C}$ the capped mRNA was extracted and purified using RNAeasy columns (Qiagen, Crawley, UK). Transcripts were then analyzed and quantified by denaturing agarose gel electrophoresis before use.

\section{Dendritic cell culture and mRNA transfection}

Fresh heparinised, peripheral blood samples were obtained from HLA-A2 positive, normal subjects, according to a protocol approved by The Kings College
Hospital Ethical Committee (LREC Protocol number 01/ 248). Informed, written consent was obtained and the study was performed according to the principles of World Medical Association Declaration of Helsinki. DC were derived from PBMC essentially as described by Romani et al [23]. Adherent cells $\left(7 \times 10^{6}\right.$ per well of 6 -well plates; Nunc, UK) were cultured at $37^{\circ} \mathrm{C}$ for 7 days in X-Vivo, $1 \%$ autologous plasma, and $800 \mathrm{u} / \mathrm{ml} \mathrm{GM-CSF}$ plus $500 \mathrm{u} / \mathrm{ml}$ interleukin-4 (IL-4) (both from R\&D Systems, Abingdon, UK) with cytokine replenishment after 3 days.

Immature $\mathrm{DC}$ were transfected with mRNA by electroporation in $400 \mu \mathrm{L}$ of X-Vivo with no supplements in a $4 \mathrm{~mm}$ cuvette using the Easy-ject plus system (Equibio, Ashford, UK) at $300 \mathrm{~V}$ and $150 \mu \mathrm{F}$ and a pulse time of 4 $\mathrm{ms}$. After electroporation, DC were resuspended in $3 \mathrm{ml}$ of X-Vivo with antibiotics and rested for 1 hour.

\section{ELISPOT and T cell proliferation assays}

PBMC were depleted of HLA class II positive cells, using anti-HLA Class II-coated magnetic particles (Dynabeads, Dynal Biotech, Wirral, UK). ELISPOT assay (U-Cytech, Netherlands) was performed to determine the number of cells producing interferon-gamma. Briefly, HLA class IIdepleted cells were seeded in 96 well plates $\left(1 \times 10^{5} /\right.$ well $)$ and co-cultured with autologous, $\gamma$-irradiated $(4,000$ rads), matured DC $\left(1 \times 10^{4} /\right.$ well $)$ in serum-free X-Vivo medium supplemented on days 1,3 and 7 of culture with IL-2 $(20 \mathrm{U} / \mathrm{ml})$ and IL-7 $(10 \mathrm{ng} / \mathrm{ml})$ (both from R\&D systems, UK). Cells were re-stimulated after 7 days with autologous, $\gamma$-irradiated, matured DC $\left(1 \times 10^{4} /\right.$ well $)$ in the presence of IL-2 and IL-7 and 24 hours after the second stimulation with antigen-loaded $\mathrm{DC}, \mathrm{T}$ cells were washed and plated at $1 \times 10^{5}$ cells/well of the ELISPOT plates, which were incubated for 5 hours before being washed and developed. T cells supplemented with PHA $(10 \mu \mathrm{g} / \mathrm{ml})$ acted as a positive control.

To assess $\mathrm{T}$ cell proliferation, HLA class II-depleted cells were seeded in 96 well plates $\left(1 \times 10^{5} /\right.$ well $)$ and cocultured with autologous, $\gamma$-irradiated (4,000 rads), matured DC $\left(1 \times 10^{4} /\right.$ well $)$ in serum-free X-Vivo medium supplemented on days 1,3 and 7 of culture with IL-2 (20 $\mathrm{U} / \mathrm{ml}$ ) and IL-7 (10 ng/ml) (both from R\&D systems, UK). Cells were re-stimulated after 7 days with autologous, $\gamma$ irradiated, matured DC $\left(1 \times 10^{4} /\right.$ well $)$ in the presence of IL-2 and IL-7 and cultures incubated for a further 5 days; ${ }^{3} \mathrm{H}$-thymidine (Amersham Pharmacia Biotech, Amersham, Bucks, UK) was added for the last 18 hours of culture. DC were either transfected with mRNA or pulsed with $1 \mu \mathrm{M}$ peptides for 3 hours, and matured with LPS (100 ng/ml) (Sigma, UK) for 16 hours.

\section{Chromium release assay}

A chromium release assay was used to assess the ability of CTL to lyse target cells. Briefly, PBMC were enriched for 
a

SP6 Transcription start
\begin{tabular}{|c|c|c|c|c|}
\hline 5'UTR & Kozak & ORF & 3'UTR & Poly A \\
\hline Nhe1 & \multicolumn{3}{c}{ Age1 } \\
SnaB1
\end{tabular}

b

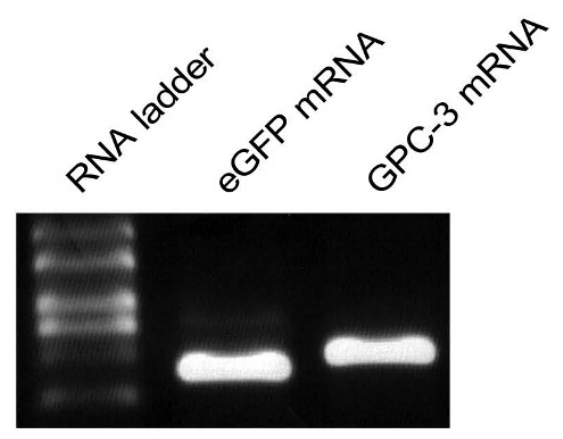

d

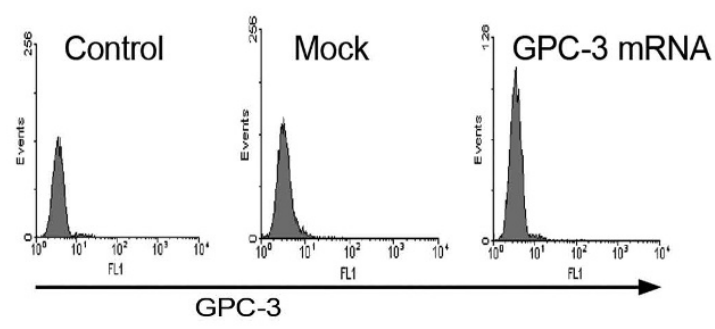

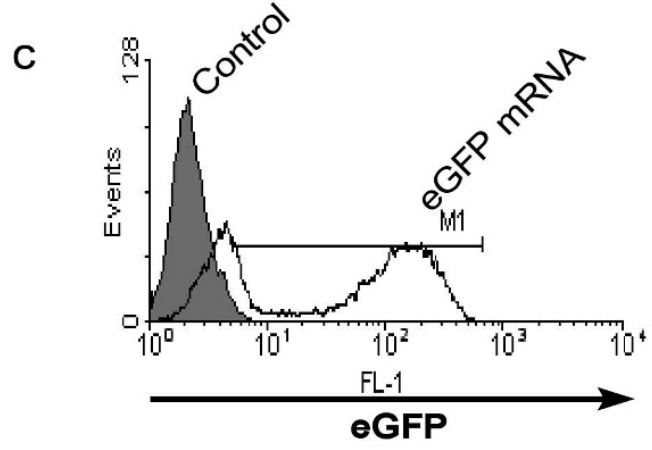

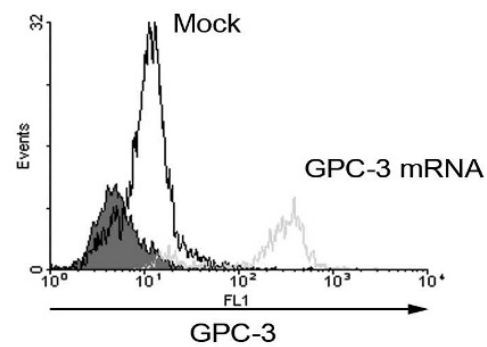

Figure 1 Expression of transgenes in monocyte-derived dendritic cells following transfection by electroporation of mRNA. a. Diagram of expression vector between SP6 transcription initiation site and SnaB1 restriction enzyme site. $\mathbf{b}$. Denaturing agarose gel showing in vitro transcribed eGFP and GPC-3 mRNA. c. eGFP expression in monocyte-derived DC as determined by flow cytometry, 20 hours after mock transfection (filled area) or transfection with $20 \mathrm{\mu g}$ eGFP mRNA (open area), when 64\% of DC were positive for eGFP. d. GPC-3 expression in matured, monocyte-derived DC as determined by flow cytometry after staining with anti-GPC-3 antibody; left panel shows cell surface expression of GPC-3, 20 hours after mock transfection or transfection with $20 \mu \mathrm{g}$ GPC-3 mRNA, staining with isotype control antibody is shown for comparison; right panel shows intracellular expression after DC were permeabilised by drop-wise addition of the cells to ice cold 70\% ethanol, 20 hours after mock transfection (thick line) or transfection with $20 \mu \mathrm{g} \mathrm{GPC}-3 \mathrm{mRNA}$ (pale line), staining with isotype control antibody is shown for comparison (filled area).

CD8+ cells by depletion of CD4+ cells using anti-CD4 microbeads (MACS beads, Miltenyi Biotec, Bergisch Gladbach, Germany) and these cells $\left(1 \times 10^{6}\right.$ cells/well $)$ were co-cultured with autologous, $\gamma$-irradiated $(4,000$ rads) DC $\left(1 \times 10^{5}\right.$ cells/well in 6 well plates $)$, which had been pulsed with $1 \mu \mathrm{M}$ peptides for 3 hours and matured with LPS (100 ng/ml) for 16 hours. Cells were cultured in serum-free X-Vivo medium supplemented on days 1,3 and 7 with IL-2 $(20 \mathrm{U} / \mathrm{ml})$ and IL-7 $(10 \mathrm{ng} / \mathrm{ml})$ (both from R\&D systems, UK). Cells were re-stimulated after 7 days with peptide-pulsed DC and, 5 days after the second stimulation, the cytotoxic activity of the expanded $\mathrm{T}$ cells was measured by chromium release assay. Target cells (HepG2) were labelled with $200 \mu \mathrm{Ci} \mathrm{Na}_{2}{ }^{51} \mathrm{CrO}_{4}$ (Amersham, UK) in $0.5 \mathrm{ml}$ DMEM containing $10 \%$ FCS for 60 minutes at $37^{\circ} \mathrm{C}$. The cells were washed 3 times with warm medium and plated at $5 \times 10^{3}$ cells/well in roundbottomed 96 well plates (Nunc). Effector cells were added at graded effector/target ratios in a final volume of $200 \mu \mathrm{l} /$ well. After 4 hours incubation at $37^{\circ} \mathrm{C}, 50 \mu \mathrm{l}$ of the culture supernatant was harvested and radioactivity counted in a scintillation counter (Beckmann, USA). For controls, maximum chromium release was achieved by the addition of $10 \%$ Triton-X and spontaneous release was 
assessed with medium alone. Percentage specific lysis was calculated as (Experimental release - spontaneous release)/(Maximum release - spontaneous release) $\times 100$. All determinations were made in triplicate.

\section{Statistical analysis}

All statistical analysis was performed using the Statistical Program for Social Sciences (SPSS 14.0 for Windows; SPSS Inc., Chicago, Illinois, USA), using the Mann-Whitney test for unpaired and the Wilcoxon Signed Ranks test for paired data. A difference between two variables was considered significant when the two-tailed $P$ value was $<$ 0.05 .

\section{Results \\ Expression of transgenes in monocyte-derived dendritic cells following electroporation of mRNA}

The yield of each SP6 mMessage Machine reaction was around $20 \mu \mathrm{g}$ of capped mRNA from $1 \mu \mathrm{g}$ of linear DNA template. Transcripts were extracted using RNAeasy columns and the quality of the mRNA confirmed by denaturing agarose gel electrophoresis (Figure 1b). Electroporation of $20 \mu \mathrm{g}$ eGFP mRNA into monocytederived DC resulted in $64 \%$ of DC expressing eGFP at 20 hours after transfection, as assessed by FACS analysis (Figure 1c). Monocyte-derived DC transfected with $20 \mu \mathrm{g}$ GPC-3 mRNA and matured with LPS were stained with anti GPC-3 antibody $(1 \mu \mathrm{g} / \mathrm{ml})$ and analyzed by flow cytometry but cell surface expression of GPC-3 could not be detected (Figure 1d left panel) until DC were permeabilised, by drop-wise addition of the cells to ice cold 70\% ethanol (Figure 1d right panel). These findings demonstrate that transfection of DC with the synthetic mRNA resulted in high levels of expression of GPC-3 or the control protein, eGFP.

\section{T cells generated by DC transfected with GPC- 3 mRNA are functional in vitro}

GPC-3 mRNA transfected DC but not mock transfected DC induced proliferation of autologous $\mathrm{T}$ cells (Figure 2a), indicating that $\mathrm{T}$ cells reacting to GPC-3 epitopes are represented in the peripheral $\mathrm{T}$ cell repertoire. ELISPOT assay for interferon-gamma production found that $\mathrm{DC}$ expressing GPC-3 generated significantly more $\mathrm{T}$ cells producing interferon-gamma than mock transfected DC ( $53 \pm 15$ versus $4 \pm 3$ spots per well, respectively; $\mathrm{p}<0.01$ ) (Figure $2 \mathrm{~b}$ ). These data demonstrate that monocytederived DC transfected with GPC-3 mRNA and matured with LPS were able to process and present GPC-3 derived epitopes, resulting in the proliferation of autologous $\mathrm{T}$ cells, which were functional as assessed by interferongamma production.

\section{Assessment of binding affinity of GPC-3 peptides to HLA-} A2

Among the 6 GPC-3 peptides tested, peptides 1, 2, 4 and 5 (GPC-3 229-237, 522-530, 186-194 and 222-230, respectively) showed significant binding affinities, whereas peptides 3 and 6 (GPC-3 299-307 and 169-177, respectively) did not show significant binding under the conditions used in these experiments (Figure 3). However, none of the GPC-3 peptides exhibited very strong binding to HLA-A2, as all demonstrated weaker binding than the "immunodominant" AFP peptide (GVALQT$\mathrm{MKQ})$.

\section{Induction of functional T cells in vitro by GPC-3 peptide- loaded DC}

Since the binding of a peptide to MHC class I molecules does not necessarily mean that the epitope will be able to induce MHC-restricted CTL, we examined whether these peptides could generate peptide-specific $\mathrm{T}$ cells from normal subjects. Peptide 2 GPC- $3_{522-530}$ FLAELAYDL, peptide 4 GPC- $3_{186-194}$ GLPDSALDI, and peptide 5 GPC-3 $222-230$ SLQVTRIFL were presented by HLA-A2, inducing $\mathrm{T}$ cell proliferation, as assessed by thymidine incorporation, in all donors to a level similar to that induced by DC loaded with the "immunodominant" AFP peptide (Figure 4a). Although, peptide 1 had shown high affinity binding to HLA-A2, only 1 out of the 3 subjects had highly reactive $\mathrm{T}$ cell proliferation to this epitope. $\mathrm{DC}$ loaded with peptides 3 and 6 were unable to stimulate autologous $\mathrm{T}$ cell responses in 2 subjects and induced only low level $\mathrm{T}$ cell proliferation in the other. These data showed a good correlation between the peptide's observed binding affinity for HLA-A2 and the ability of $\mathrm{DC}$ loaded with peptide to induce autologous $\mathrm{T}$ cell proliferation.

$\mathrm{T}$ cell function was assessed by their ability to lyse chromium-labelled HepG2 cells (HLA-A2+, GPC-3+) as targets. CD8+ enriched $\mathrm{T}$ cells were stimulated twice by autologous, $\gamma$-irradiated, peptide-pulsed, matured DC. T cells harvested after two rounds of stimulation with DC pulsed with GPC-3 peptides 2 or 5 , or the "immunodominant" AFP peptide efficiently lysed HepG2 cell targets (Figure 4b). Notably, although T cells were generated by DC loaded with GPC-3 peptide 4 , GPC- $3_{186-194}$ GLPDSALDI, they were not significantly better at lysing targets than $\mathrm{T}$ cells stimulated by control, unpulsed DC. This finding suggests that either CTL reacting against this epitope (GPC $3_{186-194}$ GLPDSALDI) were ineffective or this epitope was not generated by the proteasome in HepG2 cells and hence not presented in association with HLA-A2 at the cell surface. There were insufficient CD8+ $\mathrm{T}$ cells generated against epitope $\mathrm{GPC}_{186-194}$ GLPD- 
a

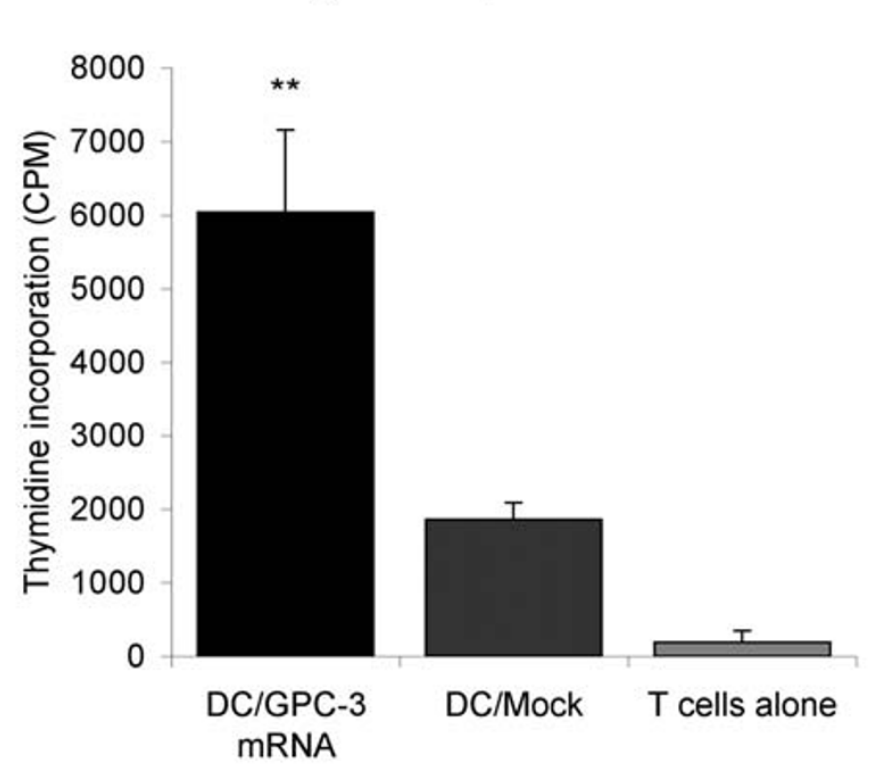

Stimulators b

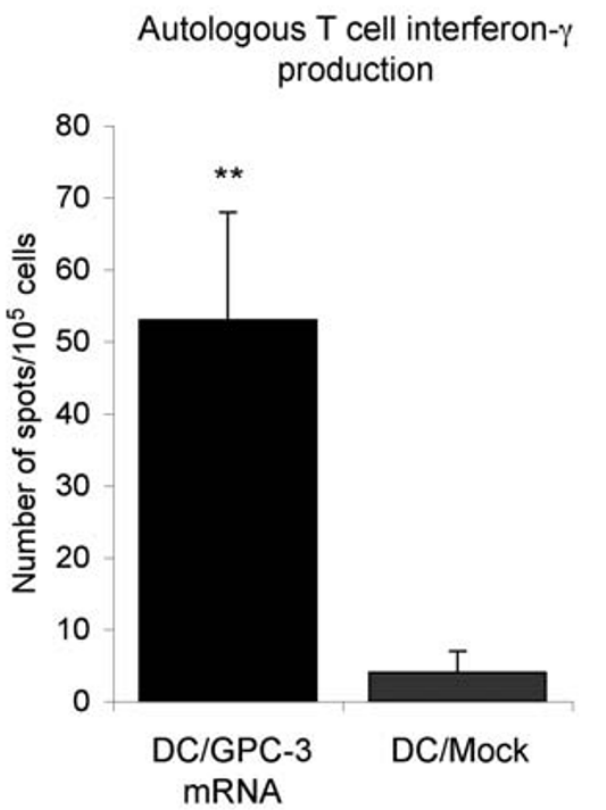

Stimulators

Figure 2 T cells generated by DC transfected with GPC-3 mRNA are functional in vitro. PBMC were depleted of HLA class II positive cells and cocultured with autologous, Y-irradiated, LPS matured DC in serum-free X-Vivo medium supplemented on days 1,3 and 7 of culture with IL-2 (20 U/ml) and IL-7 (10 ng/ml). After 7 days, T cells were re-stimulated with the same DC for a further 5 days. a. T cell proliferation $\left(1 \times 10^{5} /\right.$ well) was measured by ${ }^{3} \mathrm{H}$-thymidine incorporation, T cells were cultured alone, with DC $\left(1 \times 10^{4} /\right.$ well $)$ transfected with $20 \mu \mathrm{g} \mathrm{GPC}-3 \mathrm{mRNA}$, or mock transfected DC. $\mathbf{b}$. ELISPOT assay for interferon- $\gamma$ production was performed on T cells $(1 \times 105 /$ well) stimulated by DC transfected with $20 \mu \mathrm{GPC}-3$ mRNA or mock transfected DC.

SALDI to test whether they could lyse targets pulsed with GLPDSALDI peptide.

\section{Processing of HLA-A2-restricted GPC-3 epitopes by mRNA transfected DC}

On the basis of the above results, GPC-3 peptide epitopes 2 and 5 were selected for further investigation to establish whether these epitopes are generated and presented in association with HLA-A2 by DC transfected with GPC-3 mRNA. T cell pools were generated by stimulation of PBMC with autologous, irradiated, matured DC pulsed with $1 \mu \mathrm{M}$ GPC-3 or irrelevant control peptides, or with autologous, irradiated, matured DC transfected with GPC-3 mRNA or eGFP mRNA, as control. A second round of stimulation was performed with autologous, irradiated, matured DC pulsed with $1 \mu \mathrm{M}$ GPC-3 or irrelevant control peptides. DC pulsed with peptide 2 (GPC$3_{522-530}$ FLAELAYDL) not only induced proliferation in $\mathrm{T}$ cells previously expanded by DC pulsed with the same peptide, as expected, but also in $\mathrm{T}$ cells previously expanded by DC transfected with GPC-3 mRNA but not eGFP mRNA, indicating that the GPC-3 mRNA transfected DC expressed HLA-A2/FLAELAYDL complex on the cell surface and were able to expand viable CD8+ T cell precursors. Hence, the GPC- $3_{522-530}$ FLAELAYDL epitope is generated by the MHC class I processing pathway in DC. In contrast, although DC pulsed with peptide 5 (GPC- $3_{222-230}$ SLQVTRIFL) induced proliferation in $\mathrm{T}$ cells previously expanded by DC pulsed with the same peptide, they failed to stimulate proliferation of $\mathrm{T}$ cells previously expanded by DC transfected with either GPC3 mRNA or eGFP mRNA, suggesting that the epitope, SLQVTRIFL, was not processed for presentation in association with HLA-A2 in the GPC-3 mRNA transfected DC (Figure 5).

\section{Discussion}

In this study, we show that $\mathrm{T}$ cells reacting to GPC-3 epitopes are represented in the peripheral $\mathrm{T}$ cell repertoire of normal human subjects. Despite being exposed to this oncofoetal protein during embryonic development not all GPC-3-specific $\mathrm{T}$ cells were deleted during the ontogeny of the immune system. The data clearly demonstrate that monocyte-derived DC electroporated with GPC-3 mRNA efficiently presented GPC-3 epitopes to autologous $\mathrm{T}$ cells and generated functional GPC-3-reactive $\mathrm{T}$ cells in vitro as shown by production of interferongamma. 

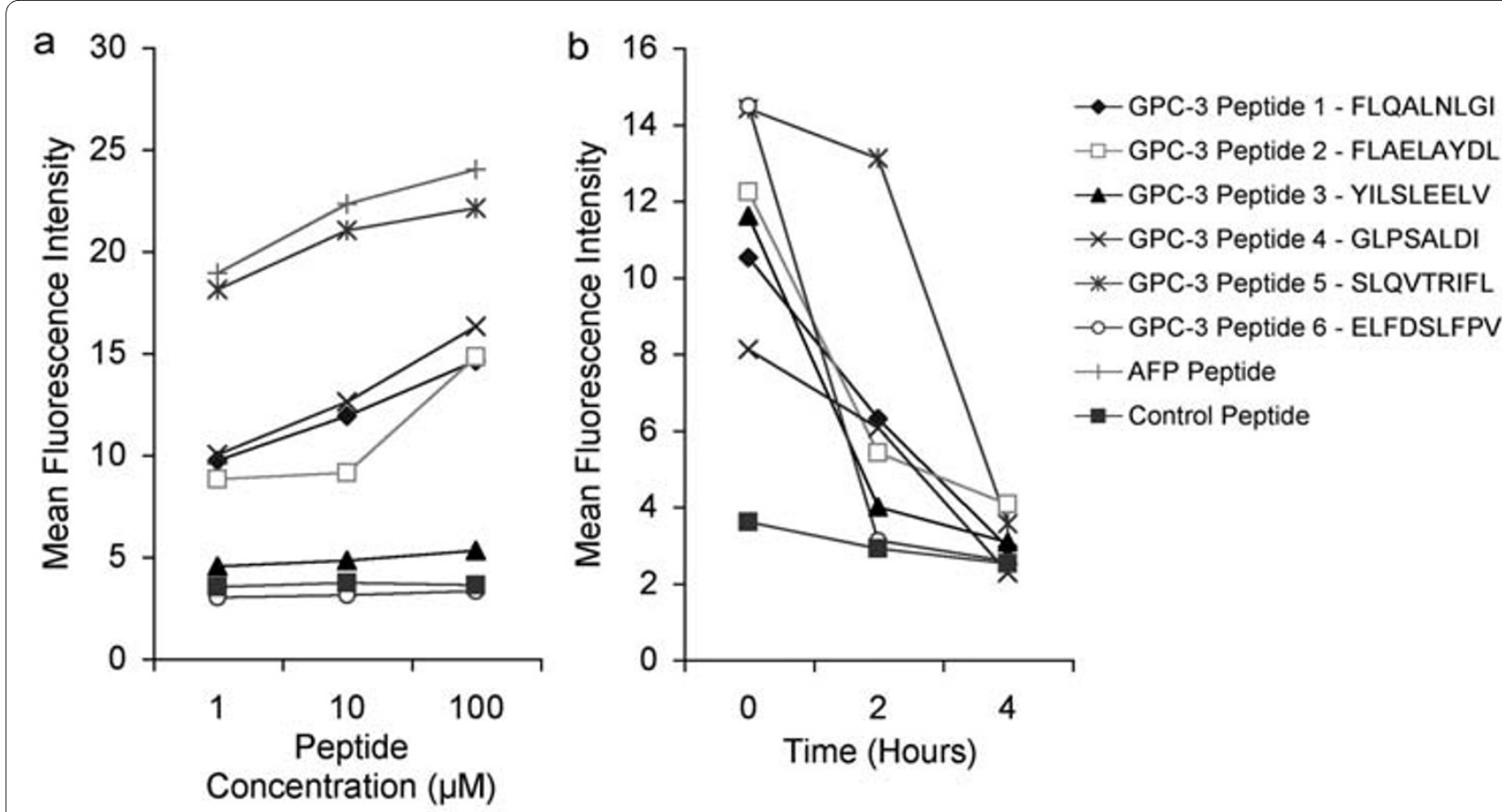

Figure 3 Binding affinity of GPC-3 peptides to HLA-A2. T2 cells were plated into 96-well U-bottomed plates at $1 \times 10^{5}$ cells per well in $200 \mu \mathrm{L} X-$ Vivo (Biowhittaker) and cultured overnight at $18^{\circ} \mathrm{C}$ to increase cell surface HLA-A2 expression. a. 3 hours after pulsing with increasing concentration of GPC-3 peptides, positive control (AFP) peptide or negative control (random) peptide plus $5 \mathrm{nM} \beta_{2}$ microglobulin and incubation at $37^{\circ} \mathrm{C}$, T2 cells were stained with a FITC-conjugated HLA-A2 specific antibody and examined by flow cytometry; $\mathbf{b}$. T2 cells were stained with a FITC-conjugated HLAA2 specific antibody and examined by flow cytometry at time points after the cells had been incubated for 3 hours at $37^{\circ} \mathrm{C}$ with $100 \mu \mathrm{M}$ peptide, 5 $\mathrm{nM} \beta_{2}$ microglobulin and $5 \mu \mathrm{g} / \mathrm{ml}$ Brefeldin A. The data shown are representative of three independent experiments.

Several studies have confirmed the very high sensitivity and specificity of GPC-3 over-expression for differentiating HCC from non-malignant liver tissue [9,24-28]. Nonetheless, a recent study reported GPC-3 immunoreactivity in inflammatory liver biopsies from patients with chronic hepatitis $C$ [29] and a further study reported the up-regulation of GPC-3 in monocyte-derived DC after maturation [30]. The discovery of GPC-3 protein in nonmalignant adult tissue, whether inflamed liver or mature DC, challenges the hypothesis that GPC-3 is a potential target TAA for HCC immunotherapy because of the spectre that the generation of GPC-3-reactive $\mathrm{T}$ cells would induce auto-immune disease. Reassuringly, in the present study, flow cytometry analysis after staining permeabilised, monocyte-derived DC with a labelled antiGPC-3 monoclonal antibody detected intracellular staining of GPC-3 only in matured, GPC-3 mRNA transfected DC and not in matured, control DC; we did not detect surface expression of GPC-3 in any DC. The reason for the discrepancy between our findings and those of Wegrowski et al [30] needs further investigation, but they utilised RT-PCR to detect GPC-3 mRNA and Western blot to detect the protein both of which are more sensitive assays than the flow cytometry analysis used in the present study. However, it should be emphasised that there was no evidence of stimulation of GPC-3-specific T cells by control DC in the present study. Murine studies have also provided reassuring data, as DC modified to express GPC-3 were shown to elicit effective antitumor immunity with no evidence of induction of autoimmune injury to liver or other organs $[12,13,31]$.

Mature GPC-3 is modified post-translation into a heparan sulphate proteoglycan [8]. Although the addition of the carbohydrate moiety could potentially mask some and generate other novel B-cell epitopes, it will not interfere with the presentation of MHC class I-restricted epitopes to CD8 + T cells. Previously, it was believed that mature cellular proteins were the main source of antigenic peptides but it is now known that MHC class I peptides originate predominantly from newly synthesised proteins [32], around 30\% of which are immediately polyubiquitinylated and subsequently cleaved by the proteasome. The resulting peptides of 8-11 residues in length are then transported into the endoplasmic reticulum, by the transporter associated with antigen presentation (TAP) complex, where they are assembled with MHC class I molecules [33]. Given that newly synthesised GPC3 protein will be processed by the proteasome before post-translational modification, the carbohydrate moiety will not affect the presentation of peptide epitopes by 


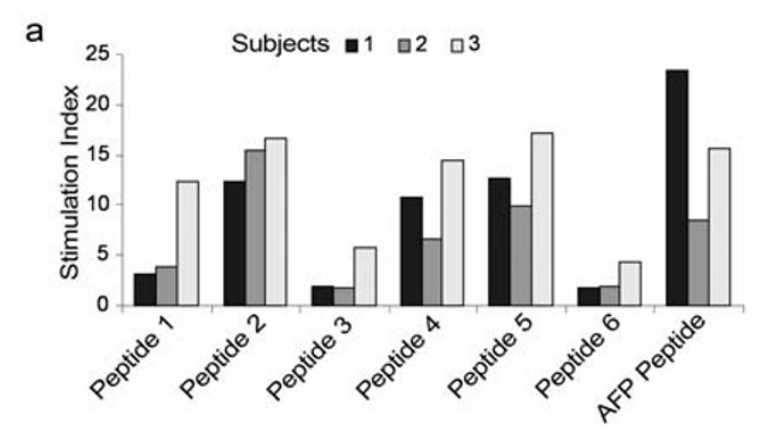

b

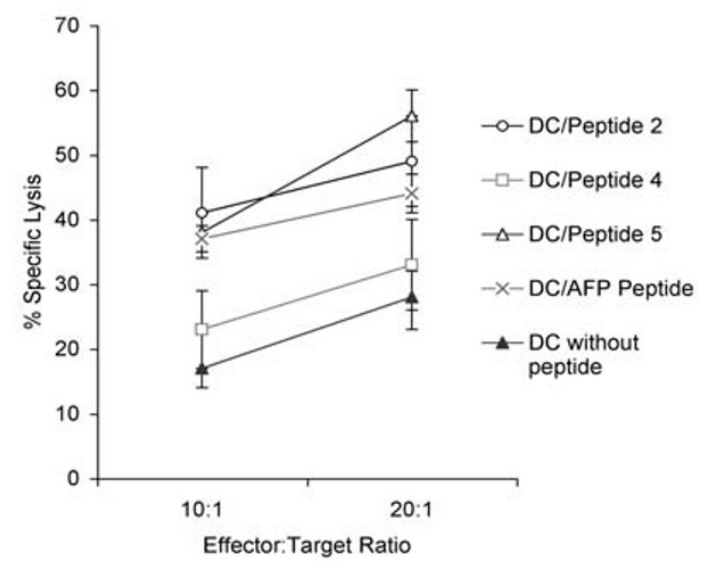

Figure 4 Induction of functional T cells in vitro by GPC-3 peptideloaded DC. a. PBMC $\left(1 \times 10^{5} /\right.$ well), depleted of HLA class II positive cells, from 3 healthy HLA-A2 positive subjects were stimulated twice with autologous, monocyte-derived DC $\left(1 \times 10^{4} /\right.$ well $)$, which had been pulsed with $1 \mu \mathrm{M}$ peptides for 3 hours, matured with LPS and $y$-irradiated, in serum-free X-Vivo medium supplemented with IL-2 $(20 \mathrm{U} / \mathrm{ml})$ and IL-7 (10 ng/ml). T cell proliferation was measured by ${ }^{3} \mathrm{H}$-thymidine incorporation, Stimulation Index is ratio of T cell proliferation due to peptide-pulsed $D C \div$ control DC. b. CD8+ enriched T cells were stimulated twice by autologous, $Y$-irradiated, peptide-pulsed, matured DC. The ability of these CD8+ T cells to lyse HepG2 cells was assessed by chromium release assay. Target cells (HepG2) were labelled with 200 $\mu \mathrm{Ci} \mathrm{Na}{ }_{2}{ }^{51} \mathrm{CrO}_{4}$ and plated $\left(5 \times 10^{3}\right.$ cells/well) in round-bottomed 96 well plates. Effector cells were added at graded effector/target ratios and after 4 hours incubation at $37^{\circ} \mathrm{C}, 50 \mu$ l of the culture supernatant was harvested and radioactivity counted in a scintillation counter. Spontaneous release was $<15 \%$ in all assays. Error bars reflect standard error of mean of 3 experiments.

MHC class I molecules. CD8+ T cell receptors recognise only GPC-3 epitopes expressed in association with MHC class I molecules rather than the intact mature protein at the cell surface.

A second aim of this study was to identify HLA-A2restricted epitopes derived from GPC-3. When we analyzed the amino acid sequence of human GPC-3, 6 sequences were identified that were predicted both to bind to HLA-A2 and to be processed by the proteasome. We used flow cytometry analysis of $\mathrm{T} 2$ cells, which are

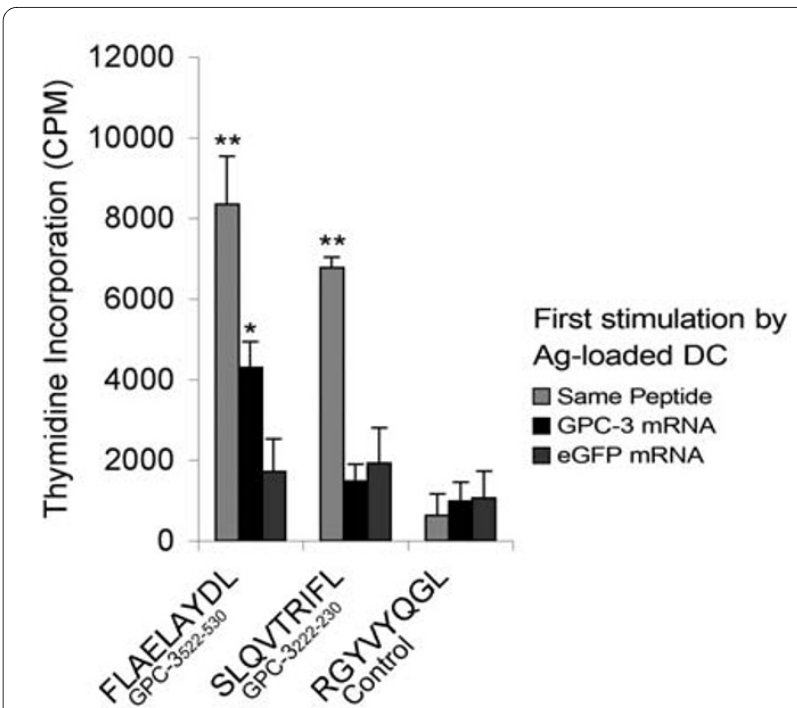

$2^{\text {nd }}$ stimulation with peptide-loaded DC

Figure 5 Processing of HLA-A2-restricted GPC-3 epitopes by mRNA transfected DC. T cell pools were expanded firstly by a round of stimulation with autologous, irradiated, matured DC pulsed with 1 $\mu M$ GPC-3 or irrelevant control peptides, or DC transfected with either GPC-3 mRNA or eGFP mRNA as control, followed by a second round of stimulation with autologous, irradiated, matured DC pulsed with $1 \mu \mathrm{M}$ GPC-3 or irrelevant control peptides. T cell proliferation was assessed by thymidine incorporation, at a stimulator to responder ratio of 1:10. ${ }^{*} p<0.05$ and ${ }^{* *} p<0.01$ compared to T cells stimulated in the first round by eGFP mRNA transfected DC; error bars reflect standard error of mean of 3 experiments.

TAP deficient, to measure the half-life of peptide binding to HLA-A2 and identified 4 peptides with prolonged, high affinity binding for HLA-A2. Of these, GPC- $3_{522-530}$ FLAELAYDL, fulfilled our criteria as a naturally processed, HLA-A2-restricted CTL epitope because: i) it was generated by the MHC class I processing pathway in DC transfected with GPC-3 mRNA, and ii) HLA-A2 positive, monocyte-derived DC loaded with the peptide stimulated proliferation in autologous $\mathrm{T}$ cells and generated CTL that lysed HLA-A2 and GPC-3 positive tumour cells. One of the peptides GPC- $3_{169-177}$ ELFDSLFPV predicted to have strong binding to HLA-A2 was found to rapidly dissociate from HLA-A2 in the present study and DC loaded with this peptide did not stimulate autologous T cells in HLA-A2 positive subjects, a finding confirmed by Nishimura and colleagues who found that DC loaded with GPC-3 ${ }_{169-177}$ ELFDSLFPV were unable to induce CTL or T cells producing interferon-gamma [34].

Previously, Komori et al used HLA-A2.1 transgenic mice to identify HLA-A2 ( $A * 0201)$-restricted GPC-3 epitopes but found no evidence that CTL were generated against GPC- $3_{522-530}$ FLAELAYDL in animals immunized with DC pulsed with a mixture of peptides because, after 
spleen cell harvest, only CD4- $\mathrm{T}$ cells stimulated in vitro with the peptide GPC- $3_{144-152}$ FVGEFFTDV produced high levels of interferon- $\gamma[31]$. These findings suggest that the epitope GPC- $3_{144-152}$ might be immunodominant in this system or, alternatively, CTL reactive to GPC- $3_{522-}$ ${ }_{530}$ may not have been generated in HLA-A2.1 transgenic mice due to differences in the $\mathrm{T}$ cell repertoire between mice and humans, resulting in some HLA-A2-restricted epitopes being recognized only by human $\mathrm{T}$ cells. Nondominant epitopes, although having a weaker affinity to MHC, can still induce reactive CTL with cytotoxic activity and thus be applicable for immunotherapy [35]. Indeed, $\mathrm{T}$ cells responding to such epitopes are often better represented in the peripheral $\mathrm{T}$ cell repertoire because those responding to self-epitopes with strong MHC binding are more likely to be deleted in the thymus during the ontogeny of the immune system [36].

Three additional GPC-3 peptides found to have high affinity binding for HLA-A2 in the present study are thought to be less suitable for further clinical investigation because either $\mathrm{T}$ cells from the peripheral $\mathrm{T}$ cell repertoire were poorly reactive (peptide $1, \mathrm{GPC}-3_{229-237}$ FLQALNLGI), or the epitopes were not generated by the MHC class I processing pathways in the HCC cell line used as the target cell for the CTL assay (peptide 4, GPC$3_{186-194}$ GLPDSALDI) or in the DC (peptide 5, GPC- $3_{222-}$ ${ }_{230}$ SLQVTRIFL). Interestingly, CTL generated by DC loaded with peptide 5 effectively lysed HepG2 cells, indicating that it was expressed in association with HLA-A2 on the surface of the tumour cells, possibly reflecting differences in the cleavage of the GPC-3 polypeptide by the constitutive proteasome in the tumour cell line and the immunoproteasome in DC [37]. Variable numbers of $\mathrm{CD} 8+$ precursor $\mathrm{T}$ cells in the small number of donors tested or less efficient presentation of peptide 5 by the DC, relative to peptide 2 , seem unlikely explanations for the findings as two rounds of stimulation by DC loaded with peptide 5 induced high levels of $\mathrm{T}$ cell proliferation and functional CTL in all subjects tested.

GPC-3 appears to be an eminently suitable target molecule for HCC immunotherapy because it is a foetal protein [8] that is expressed early in the development of HCC [38] and has been implicated directly in tumour progression. Membrane bound GPC-3 has been postulated to stimulate the growth of HCC by both facilitating the interaction of Wnt with its signalling receptors [39] and enhancing fibroblast growth factor 2 signalling [40]. Activation of the canonical Wnt pathway is a frequent event associated with the malignant transformation of hepatocytes [41], leading to a rise in $\beta$-catenin in the nucleus, which in turn regulates transcription factors controlling hepatoma cell growth $[42,43]$. Knockdown of GPC-3 was found to attenuate fibroblast growth factor 2 binding, a mitogen that promotes HCC cell proliferation and migration by activating downstream protein kinase pathways [40]. In addition, GPC-3 expression stimulates the recruitment of macrophages into $\mathrm{HCC}$, especially macrophages with a phenotype promoting tumour progression and metastasis [44]. Therefore, although the generation of escape mutants due to loss of expression or mutation of a TAA could lead to the failure of immunotherapy, loss of GPC-3 expression by HCC, under the selective pressure of attack by antigen specific $\mathrm{T}$ cells, is likely to be mitigated by diminished tumour growth and invasiveness.

\section{Conclusions}

The findings of this study confirm previous reports that electroporation of mRNA encoding a TAA is an efficient method to load human monocyte-derived DC with antigen [45]. GPC-3 mRNA transfected DC generated GPC3 -reactive $\mathrm{T}$ cells that were functional, as shown by interferon-gamma production.

This study also identified a peptide, GPC- $3_{522-530}$ FLAELAYDL, that fulfilled criteria as a naturally processed, HLA-A2-restricted CTL epitope. We anticipate that this epitope and the HLA-A2-restricted GPC-3 epitope, GPC3 ${ }_{144-152}$ FVGEFFTDV, identified by a previous HLAA2 transgenic mouse study [31], can be utilized to monitor CTL responses in patients undergoing immunotherapy studies of GPC-3-loaded DC. These studies will determine the probability of successful generation of HLA-A2-restricted CTL reactive to these epitopes in patients with malignancy.

\section{List of abbreviations}

GPC-3: glypican-3; HCC: hepatocellular carcinoma; PBMC: peripheral blood mononuclear cells; DC: dendritic cells; LPS: Lipopolysaccharide; TIL: tumour infiltrating lymphocytes; IL-2: interleukin 2; TAA: tumourassociated antigens; CTL: cytotoxic T lymphocyte; TAP: transporters associated with antigen processing; IL-4: interleukin-4; eGFP: enhanced green fluorescent protein.

\section{Competing interests}

The authors declare that they have no competing interests.

\section{Authors' contributions}

JOB generated the GPC-3 CDNA and inserted it into the mRNA expression vector, carried out the immunoassays, and drafted the manuscript. FF participated in design, coordination of the study, and helped draft the manuscript. PMH conceived the study, designed the mRNA expression vector, helped to perform the statistical analysis and draft the manuscript. All authors read and approved the final manuscript.

\section{Acknowledgements}

The work was funded by a Wellcome Research Fellowship awarded to JOB but the funding body did not participate in study design, collection, analysis, and interpretation of data, nor in the writing of the manuscript and in the decision to submit the manuscript for publication. FF and PMH are funded by Kings College London. 
We would like to thank Dr Jon Mitchell for his technical assistance in constructing the mRNA expression vector and Dr Helena Daniels for her technical assistance with the T cell proliferation assays.

\section{Author Details}

1Department of Liver Studies \& Transplantation, Kings College London, Denmark Hill Campus, Bessemer Road, London, SE5 9RS, UK, 2Department of Haematological Medicine, Kings College London, The Rayne Institute Coldharbour Lane, London, SE5 9NU, UK and 3The Royal free Sheila Sherlock Liver Centre and Department of Surgery, Royal Free Hospital, Pond Street, Belsize Park, London NW3, UK

Received: 16 January 2010 Accepted: 13 May 2010

Published: 13 May 2010

\section{References}

1. Wang RF, Rosenberg SA: Human tumor antigens for cancer vaccine development. Immunol Rev 1999, 170:85-100.

2. Parkin DM, Bray F, Ferlay J, Pisani P: Global cancer statistics, 2002. CA Cancer J Clin 2005, 55:74-108.

3. O'Beirne JP, Harrison PM: The role of the immune system in the control of hepatocellular carcinoma. Eur J Gastroenterol Hepatol 2004, 16:1257-1260.

4. Gaffey MJ, Joyce JP, Carlson GS, Esteban JM: Spontaneous regression of hepatocellular carcinoma. Cancer 1990, 65:2779-2783.

5. Gao Q, Qiu SJ, Fan J, Zhou J, Wang XY, Xiao YS, Xu Y, Li YW, Tang ZY: Intratumoral balance of regulatory and cytotoxic $T$ cells is associated with prognosis of hepatocellular carcinoma after resection. J Clin Oncol 2007, 25:2586-2593.

6. Takayama T, Sekine T, Makuuchi M, Yamasaki S, Kosuge T, Yamamoto J, Shimada K, Sakamoto M, Hirohashi S, Ohashi Y, Kakizoe T: Adoptive immunotherapy to lower postsurgical recurrence rates of hepatocellular carcinoma: a randomised trial. Lancet 2000, 356:802-807.

7. Knutson KL, Wagner W, Disis ML: Adoptive T cell therapy of solid cancers. Cancer Immunol Immunother 2006, 55:96-103.

8. Iglesias BV, Centeno G, Pascuccelli H, Ward F, Peters MG, Filmus J, Puricelli L, de Kier Joffe EB: Expression pattern of glypican-3 (GPC3) during human embryonic and fetal development. Histol Histopathol 2008, 23:1333-1340

9. Capurro M, Wanless IR, Sherman M, Deboer G, Shi W, Miyoshi E, Filmus J: Glypican-3: a novel serum and histochemical marker for hepatocellular carcinoma. Gastroenterology 2003, 125:89-97.

10. Shirakawa H, Suzuki H, Shimomura M, Kojima M, Gotohda N, Takahashi S, Nakagohri T, Konishi M, Kobayashi N, Kinoshita T, Nakatsura T: Glypican-3 expression is correlated with poor prognosis in hepatocellular carcinoma. Cancer Sci 2009, 100:1403-1407.

11. Motomura Y, Ikuta Y, Kuronuma T, Komori H, Ito M, Tsuchihara M, Tsunoda Y, Shirakawa H, Baba H, Nishimura Y, Kinoshita T, Nakatsura T: HLA-A2 and -A24-restricted glypican-3-derived peptide vaccine induces specific CTLs: preclinical study using mice. Int J Oncol 2008, 32:985-990.

12. Nakatsura T, Komori H, Kubo T, Yoshitake Y, Senju S, Katagiri T, Furukawa Y, Ogawa M, Nakamura Y, Nishimura Y: Mouse homologue of a novel human oncofetal antigen, glypican-3, evokes T-cell-mediated tumor rejection without autoimmune reactions in mice. Clin Cancer Res 2004, 10:8630-8640

13. Motomura Y, Senju S, Nakatsura T, Matsuyoshi H, Hirata S, Monji M, Komori H, Fukuma D, Baba H, Nishimura Y: Embryonic stem cell-derived dendritic cells expressing glypican-3, a recently identified oncofetal antigen, induce protective immunity against highly metastatic mouse melanoma, B16-F10. Cancer Res 2006, 66:2414-2422.

14. Hiroishi K, Eguchi J, Baba T, Shimazaki T, Ishii S, Hiraide A, Sakaki M, Doi H, Uozumi S, Omori R, Matsumura T, Yanagawa T, Ito T, Imawari M: Strong CD8(+) T-cell responses against tumor-associated antigens prolong the recurrence-free interval after tumor treatment in patients with hepatocellular carcinoma. J Gastroenterol 2010, 45:451-458.

15. SYFPEITHI [http://www.syfpeithi.de/Scripts/MHCServer.dll/ EpitopePrediction.htm]

16. HLAmotif [http://bimas.dcrt.nih.gov]

17. RankPep [http://immunax.dfci.harvard.edu/Tools]
18. Butterfield LH, Koh A, Meng W, Vollmer CM, Ribas A, Dissette V, Lee E, Glaspy JA, McBride WH, Economou JS: Generation of human T-cell responses to an HLA-A2.1-restricted peptide epitope derived from alpha-fetoprotein. Cancer Res 1999, 59:3134-3142.

19. Butterfield LH, Meng WS, Koh A, Vollmer CM, Ribas A, Dissette VB, Faull K, Glaspy JA, McBride WH, Economou JS: T cell responses to HLA-A*0201restricted peptides derived from human alpha fetoprotein. J Immunol 2001, 166:5300-5308.

20. Levy F, Gabathuler R, Larsson R, Kvist S: ATP is required for in vitro assembly of MHC class I antigens but not for transfer of peptides across the ER membrane. Cell 1991, 67:265-274.

21. Stuber G, Leder GH, Storkus WT, Lotze MT, Modrow S, Szekely L, Wolf H, Klein E, Karre K, Klein G: Identification of wild-type and mutant p53 peptides binding to HLA-A2 assessed by a peptide loading-deficient cell line assay and a novel major histocompatibility complex class I peptide binding assay. Eur J Immunol 1994, 24:765-768.

22. Weiss IM, Liebhaber SA: Erythroid cell-specific mRNA stability elements in the alpha 2-globin 3' nontranslated region. Mol Cell Biol 1995, 15:2457-2465

23. Romani N, Reider D, Heuer M, Ebner S, Kampgen E, Eibl B, Niederwieser D, Schuler G: Generation of mature dendritic cells from human blood. An improved method with special regard to clinical applicability. $J$ Immunol Methods 1996, 196:137-151.

24. Sung YK, Hwang SY, Park MK, Faroog M, Han IS, Bae HI, Kim JC, Kim M: Glypican-3 is overexpressed in human hepatocellular carcinoma. Cancer Sci 2003, 94:259-262.

25. Nakatsura T, Yoshitake Y, Senju S, Monji M, Komori H, Motomura Y, Hosaka S, Beppu T, Ishiko T, Kamohara H, Ashihara H, Katagiri T, Furukawa Y, Fujiyama S, Ogawa M, Nakamura Y, Nishimura Y: Glypican-3, overexpressed specifically in human hepatocellular carcinoma, is a novel tumor marker. Biochem Biophys Res Commun 2003, 306:16-25.

26. Llovet JM, Chen Y, Wurmbach E, Roayaie S, Fiel MI, Schwartz M, Thung SN, Khitrov G, Zhang W, Villanueva A, Battiston C, Mazzaferro V, Bruix J, Waxman S, Friedman SL: A molecular signature to discriminate dysplastic nodules from early hepatocellular carcinoma in HCV cirrhosis. Gastroenterology 2006, 131:1758-1767.

27. Coston WM, Loera S, Lau SK, Ishizawa S, Jiang Z, Wu CL, Yen Y, Weiss LM, Chu PG: Distinction of Hepatocellular Carcinoma From Benign Hepatic Mimickers Using Glypican-3 and CD34 Immunohistochemistry. Am J Surg Pathol 2008, 32:433-444.

28. Anatelli F, Chuang ST, Yang XJ, Wang HL: Value of glypican 3 immunostaining in the diagnosis of hepatocellular carcinoma on needle biopsy. Am J Clin Pathol 2008, 130:219-223.

29. Abdul-Al HM, Makhlouf HR, Wang G, Goodman ZD: Glypican-3 expression in benign liver tissue with active hepatitis $C$ : implications for the diagnosis of hepatocellular carcinoma. Hum Pathol 2008, 39:209-212.

30. Wegrowski Y, Milard AL, Kotlarz G, Toulmonde E, Maquart FX, Bernard J: Cell surface proteoglycan expression during maturation of human monocytes-derived dendritic cells and macrophages. Clin Exp Immunol 2006, 144:485-493.

31. Komori H, Nakatsura T, Senju S, Yoshitake Y, Motomura Y, Ikuta Y, Fukuma D, Yokomine K, Harao M, Beppu T, Matsui M, Torigoe T, Sato N, Baba H, Nishimura Y: Identification of HLA-A2- or HLA-A24-restricted CTL epitopes possibly useful for glypican-3-specific immunotherapy of hepatocellular carcinoma. Clin Cancer Res 2006, 12:2689-2697.

32. Schubert U, Anton LC, Gibbs J, Norbury CC, Yewdell JW, Bennink JR: Rapid degradation of a large fraction of newly synthesized proteins by proteasomes. Nature 2000, 404:770-774.

33. Kloetzel PM: Antigen processing by the proteasome. Nat Rev Mol Cell Biol 2001, 2:179-187.

34. Nishimura Y, Nakatsura T, Komori H: Glypican-3 (GPC3)-Derived Tumor Rejection Antigenic Peptides Useful For HLA-A2-Positive Patients And Pharmaceutical Comprising The Same. In Patent City: Kumamoto University; 2009. AA61 K3808FI

35. Bredenbeck A, Losch FO, Sharav T, Eichler-Mertens M, Filter M, Givehchi A, Sterry W, Wrede P, Walden P: Identification of noncanonical melanomaassociated T cell epitopes for cancer immunotherapy. J Immunol 2005, 174:6716-6724

36. Anderton SM, Wraith DC: Selection and fine-tuning of the autoimmune T-cell repertoire. Nat Rev Immunol 2002, 2:487-498. 
37. Dannull J, Lesher DT, Holzknecht R, Qi W, Hanna G, Seigler H, Tyler DS, Pruitt SK: Immunoproteasome down-modulation enhances the ability of dendritic cells to stimulate antitumor immunity. Blood 2007, 110:4341-4350.

38. Jiang WJ, Man XB, Tang L, Song HY, Li SJ, Cai GJ, Qiu XH, Hu HP: Gradual upregulation of $\mathrm{OCl}-5$ expression during occurrence and progression of rat hepatocellular carcinoma. Hepatobiliary Pancreat Dis Int 2006, 5:257-261.

39. Capurro Ml, Xiang YY, Lobe C, Filmus J: Glypican-3 promotes the growth of hepatocellular carcinoma by stimulating canonical Wnt signaling. Cancer Res 2005, 65:6245-6254

40. Lai JP, Sandhu DS, Yu C, Han T, Moser CD, Jackson KK, Guerrero RB, Aderca I, Isomoto H, Garrity-Park MM, Zou H, Shire AM, Nagorney DM, Sanderson SO, Adjei AA, Lee JS, Thorgeirsson SS, Roberts LR: Sulfatase 2 upregulates glypican 3 , promotes fibroblast growth factor signaling, and decreases survival in hepatocellular carcinoma. Hepatology 2008, 47:1211-1222.

41. Suriawinata $A, X u R:$ An update on the molecular genetics of hepatocellular carcinoma. Semin Liver Dis 2004, 24:77-88.

42. Giles $\mathrm{RH}$, van Es JH, Clevers H: Caught up in a Wnt storm: Wnt signaling in cancer. Biochim Biophys Acta 2003, 1653:1-24.

43. Zeng G, Apte U, Cieply B, Singh S, Monga SP: siRNA-mediated betacatenin knockdown in human hepatoma cells results in decreased growth and survival. Neoplasia 2007, 9:951-959.

44. Takai H, Ashihara M, Ishiguro T, Terashima H, Watanabe T, Kato A, Suzuki M: Involvement of glypican-3 in the recruitment of M2-polarized tumorassociated macrophages in hepatocellular carcinoma. Cancer Biol Ther 2009, 8:2329-2338.

45. Van Tendeloo VF, Ponsaerts P, Lardon F, Nijs G, Lenjou M, Van Broeckhoven C, Van Bockstaele DR, Berneman ZN: Highly efficient gene delivery by mRNA electroporation in human hematopoietic cells: superiority to lipofection and passive pulsing of mRNA and to electroporation of plasmid CDNA for tumor antigen loading of dendritic cells. Blood 2001, 98:49-56.

Submit your next manuscript to BioMed Central and take full advantage of:

- Convenient online submission

- Thorough peer review

- No space constraints or color figure charges

- Immediate publication on acceptance

- Inclusion in PubMed, CAS, Scopus and Google Scholar

- Research which is freely available for redistribution

Submit your manuscript at www.biomedcentral.com/submit
Ciomed Central 